Healthcare

\section{What is "quality improvement" and how can it transform healthcare?}

Paul B Batalden, Frank Davidoff

\section{Transformation of healthcare-quality improvement}

M any in healthcare today are interested in defining "quality improvement". We propose defining it as the combined and unceasing efforts of everyone-healthcare professionals, patients and their families, researchers, payers, planners and educators-to make the changes that will lead to better patient outcomes (health), better system performance (care) and better professional development (learning; fig 1). This definition arises from our conviction that healthcare will not realise its full potential unless change making becomes an intrinsic part of everyone's job, every day, in all parts of the system. Defined in this way, improvement involves a substantial shift in our idea of the work of healthcare, a challenging task that can benefit from the use of a wide variety of tools and methods (table 1 ).

Although all improvement involves change, not all changes are improvement. If healthcare is going to benefit fully from the science of disease biology, we need to be sure that the changes we make systematically incorporate generalisable scientific knowledge. To guide our design of change, we need to characterise the settings in which care is actually delivered (microsystems, mesosystems and macrosystems) in sophisticated ways. Moreover, to know that change is producing improvement, we need accurate and powerful measurements of what is happening. We propose a simple formula that illustrates the way in which these forces combine to produce improvement (fig 2).

Each of the five elements in this equation is driven by a different knowledge system (table 2). The generalisable scientific knowledge we need (element $\# 1$ ) is constructed from empirical studies that work to control context as a variable, thus minimising or eliminating its effect on what is being studied. A knowledge of particular contexts (element \#2) is developed by enquiry into the identity of local care settings - their processes, habits and traditions. Knowledge on the effect of improvements on system performance (element \#3) requires special types of measurement, techniques that include time in the analysis, as all improvement involves change over time; gaining this knowledge also requires the use of balanced measures that accurately reflect the richness and complexity of the phenomena under scrutiny. The " + " symbol (element \#4) represents knowledge about the many modalities, including standardisation, forcing functions, academic detailing, and so on, which are available for applying and adapting generalisable evidence to particular contexts. The " $\rightarrow$ " symbol (element \#5) represents the knowledge required for executionwhat you need to know to "make things happen", the drivers of change, in a particular place. It requires knowing where power resides and how it is asserted; it requires knowledge of the strategic aims, the usual ways of conducting work in that setting, the ways in which people are recognised and rewarded, and the ways in which they are held accountable for their work.

Acquiring these five kinds of knowledge requires both scientific and experiential learning. Reflection on the nature of these five knowledge systems, how they grow and change, and the ways in which they work together to move evidence into practice will be essential if we are going to learn about learning. Doing so will generate a kind of "metaknowledge" that will be essential over the long run in becoming progressively better at improvement.

Of course, better knowledge by itself does not guarantee improved performance; if these five knowledge systems are going to be effective, we need to pay careful attention to the way in which we deploy them. It is one thing to expect a specially commissioned "QI team" to be actively engaged in designing and testing the many changes needed for better patient and population outcomes, better system performance and better professional development; it is quite another to expect everyone involved in healthcare to do so, and do so all the time. For the universal practice of change testing to happen, all those involved in supervising

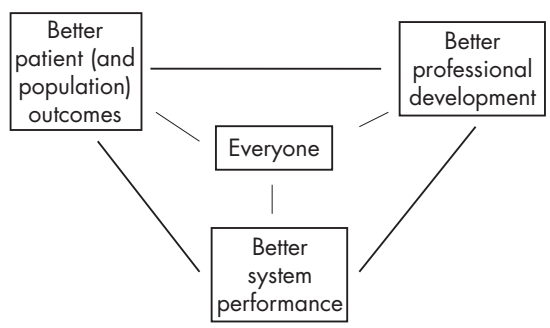

Figure 1 Linked aims of improvement.

Table 1 Illustrative tools and methods in improvement

\begin{tabular}{|c|c|}
\hline Domain of interest & Helpful tools and methods \\
\hline Healthcare as processes within systems & Diagrams that illustrate flow, inter-relationship and cause-effect; narrative descriptions; case examples \\
\hline Variation and measurement & Data recorded over time and analysed on run charts and control charts \\
\hline Customer/beneficiary knowledge & Measurements of illness burden, functional status, quality of life; recipients' assessment of the quality of their care \\
\hline $\begin{array}{l}\text { Leading, following and making changes in } \\
\text { healthcare }\end{array}$ & $\begin{array}{l}\text { Building knowledge, taking initiative or adaptive action, reviewing and reflecting; developing both leadership and } \\
\text { follower-ship skills }\end{array}$ \\
\hline Collaboration & Managing conflict, building teams and group learning; acquiring specific communication skills (eg, SBAR) \\
\hline Social context and accountability & Documenting unwanted and unnecessary variation; widespread public sharing of information \\
\hline Developing new, locally useful knowledge & Making small tests of change (PDSA cycles) \\
\hline
\end{tabular}


the work of healthcare-from the front line to the front offices-might, for example, be expected to offer specific, expert support and guidance to those they supervise as they design and execute tests of change. The model asserting that better health outcomes, better care delivery and better professional development are inextricably linked (fig 1) recognises that mutual support and stimulation among these three domains invites both sustainability and unending creativity in their efforts.

Drawing everyone actively into the process of testing change, all the time, presumes that everyone will develop a basic understanding of the standards of their work, as well as the skills they need to test changes in that work. Making improvement happen also requires leadership that enables connections between

\begin{tabular}{|c|c|c|}
\hline 1 & 2 & 3 \\
\hline $\begin{array}{l}\text { Generalisable } \\
\text { scientific } \\
\text { evidence }\end{array}$ & $\begin{array}{cc} & \text { Particular } \\
4 & \text { context }\end{array}$ & $\longrightarrow 5 \quad \begin{array}{c}\text { Measured } \\
\text { performance } \\
\text { improvement }\end{array}$ \\
\hline
\end{tabular}

Figure 2 Formula illustrating the way in which knowledge systems combine to produce improvement.
Table 2 Characteristics of five knowledge systems involved in improvement

\begin{tabular}{ll}
\hline Knowledge system & Illustrative features \\
\hline $\begin{array}{l}\text { 1. Generalisable scientific evidence } \\
\text { 2. Particular context awareness }\end{array}$ & $\begin{array}{l}\text { Controls and limits context as a variable; tests hypotheses } \\
\text { Characterises the particular physical, social and cultural identity of } \\
\text { local care settings (eg, their processes, habits and traditions) }\end{array}$ \\
3. Performance measurement & $\begin{array}{l}\text { Assesses the effect of changes by using study methods that preserve } \\
\text { time as a variable, use balanced measures (range of perspectives, } \\
\text { dimensions), analyse for patterns }\end{array}$ \\
4. Plans for change & $\begin{array}{l}\text { Describes the variety of methods available for connecting evidence to } \\
\text { particular contexts } \\
\text { 5. Execution of planned changes }\end{array}$ \\
$\begin{array}{l}\text { Provides insight into the strategic, operational and human resource } \\
\text { realities of particular settings (drivers) that will make changes happen }\end{array}$
\end{tabular}

the aims of changes and the design and testing of those changes; that pays serious attention to the policies and practices of reward and accountability; and unshakeable belief in the idea that everyone in healthcare really has two jobs when they come to work every day: to do their work and to improve it.

Qual Saf Health Care 2007;16:2-3.

doi: 10.1136/qshc. 2006.022046

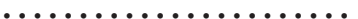

\section{Authors' affiliations}

Paul B Batalden, Center for Evaluative Sciences, Dartmouth Medical School, Hanover, New Hampshire, USA

Frank Davidoff, Institute for Healthcare

Improvement, Cambridge, Massachusetts, USA

Correspondence to: Dr P B Batalden, Center for Evaluative Sciences, Dartmouth Medical School, Hanover, NH 03755, USA

Competing interests: None declared.
In the era of public reporting and pay for performance in the UK and US, this paper raises a number of issues for how and whether to assess quality measurement among different clinical groups, using diabetes as the example. First, sample size limitations would preclude the use of mortality comparisons at the individual physician and probably at the system level as well. Furthermore, it is clear from both the current manuscript and prior work that even system level comparisons require high quality data and rigorous risk adjustment. ${ }^{4}$ Additionally, short term mortality rates may not be actionable. Consequently, the use of intermediate outcomes and process measures that have been demonstrated to reduce mortality - or at least reduce the adverse macrovascular and microvascular outcomes that result in shortened life expectancy-will undoubtedly continue to constitute the primary approach to quality assessment in diabetes.

In that regard, certain medications that have been shown in randomised clinical trials to decrease cardiovascular morbidity and mortality, such as angiotensin enzyme converting inhibitors, ${ }^{5}$ statins ${ }^{6}$ and aspirin, ${ }^{7}$ can and should be able to be successfully prescribed equally well by generalists and subspecialists for most patients. However, the situation with intermediate outcomes of glycaemia, blood pressure, and cholesterol is more 